\title{
Inuksuit: robotic astronomical site-testing stations in the Canadian High Arctic
}

\author{
Eric Steinbring*a $*^{\mathrm{a}}$ Brian Leckie ${ }^{\mathrm{a}}$, Paul Welle ${ }^{\mathrm{a}}$, Tim Hardy ${ }^{\mathrm{a}}$, Bruce Cole ${ }^{\mathrm{b}}$, Dell Bayne ${ }^{\mathrm{b}}$, Bryce Croll ${ }^{\mathrm{c}}$, \\ David E. Walker ${ }^{\mathrm{d}}$, Raymond G. Carlberg ${ }^{\mathrm{d}}$, Gregory G. Fahlman ${ }^{\mathrm{a}}$, Brad Wallace ${ }^{\mathrm{e}}$, and Paul Hickson ${ }^{\mathrm{f}}$ \\ ${ }^{a}$ National Research Council Canada, Herzberg Inst. of Astrophys., 5071 W. Saanich Rd., Victoria, \\ BC, Canada V9E 2E7; \\ ${ }^{\mathrm{b}}$ Environment Canada, 11 Innovation Blvd., Saskatoon, SK, Canada S7N 3H5 \\ ${ }^{c}$ Univ. of Toronto, Dept. of Phys. and Astron., 50 St. George Street, Toronto, ON, Canada M5S 3H4 \\ ${ }^{\mathrm{d} C}$ Cerro Tololo Inter-American Obs.; Casilla 603, La Serena, Chile \\ 'Defence Research and Development Canada, 3701 Carling Ave., Ottawa, ON, Canada K1A 0Z4; \\ ${ }^{\mathrm{f}}$ Univ. of British Columbia, Dept. of Physics and Astronomy, 6224 Agricultural Rd., Vancouver, \\ BC, Canada V6T 1Z1
}

*Eric.Steinbring@nrc-cnrc-gc.ca; phone 1250 363-3452; fax 1250 363-0045

\begin{abstract}
Coastal mountains at Canada's northern tip possess many of the desirable properties that make the Antarctic glacial plateau attractive for astronomy: they are cold, high, dry, and in continuous darkness for several months in winter. Satellite images suggest that they should also benefit from clear skies for a fraction of time comparable to the best midlatitude sites, and conventional site-selection criteria point to good seeing. In order to confirm these conditions, we are testing three mountain sites on northwestern Ellesmere Island, in Nunavut. On each we have installed a compact, autonomous site-testing station consisting of a meteorological station, a simple optical/near-infrared camera for sensing cloud cover, and - at one site - a more advanced all-sky viewing camera. The systems were deployed by helicopter and run on batteries recharged by wind (a compact methanol fuel cell is under study as a supplementary power source). Effective two-way communications via the Iridium satellite network allows a limited number of highly compressed images to be transferred. The full-winter dataset is stored at the site on flash-drives, thus requiring a return visit to retrieve, but day-to-day station performance can be assessed using telemetry and a computer model. Based on sitetesting results, the plan is to select one site for the addition of a seeing monitor and a small but scientifically productive telescope.
\end{abstract}

Keywords: site testing, Arctic

\section{INTRODUCTION}

It has been suspected for some time that mountains in the Canadian Far North could provide excellent telescope sites [1]. The mountains of the eastern Arctic archipelago are of particular interest, with many summits between 1000 and $1900 \mathrm{~m}$, reaching above the Arctic inversion [2] and thus mitigating boundary effects: the highest peak, Mount Barbeau

Ground-based and Airborne Telescopes II, edited by Larry M. Stepp, Roberto Gilmozzi, Proc. of SPIE Vol. 7012, 70121V, (2008) · 0277-786X/08/\$18 - doi: 10.1117/12.789531 
(2616 m) is almost as high as Cerro Pachon in Chile (2715 m). Such sites offer many of the benefits of the Antarctic glacial plateau, and in some ways could be superior:

- They offer a solid (rock) foundation on which to build a telescope.

- Being located as far north as a latitude of 82 degrees they offer the advantage of long Arctic nights, superior to sites further from the poles.

- Weather patterns are remarkably consistent, with winds almost always from the west (see Figure 1). Continuous weather records going back roughly 50 years are available for Eureka $(80 \mathrm{~N})$ and Alert $(82 \mathrm{~N})$ on Ellesmere Island. Daily climate normals are $-40{ }^{\circ} \mathrm{C}$ for winter and $+5{ }^{\circ} \mathrm{C}$ in summer.

- The whole of the High Arctic is polar desert, with annual precipitation less than $9 \mathrm{~cm}$ (occurring primarily in summer). For Alert, precipitation is less than $10 \mathrm{~mm}$ on average in February [3].

- The intense cold and dryness of the Arctic winter leads to very little cloud cover. Satellite data from the AVHRR (Advanced Very High Resolution Radiometer) sensor carried on the NOAA polar-orbiting satellites is publicly available as atmospheric parameters via open-source software. This provides maps of about $5 \mathrm{~km}$ resolution of winter clear-sky fractions, which are high for northwestern Ellesmere peaks [4].

Examples of scientific studies that would benefit most from a site combining long uninterrupted observing periods with a low-noise thermal-infrared sky are searches for extra-solar planets and supernovae, but sub-mm science could profit as well. The expectation is that good seeing will extend this valuable window into the optical.

Fourteen high peaks on Ellesmere Island a) with latitudes of $80 \mathrm{~N}$ or greater, b) within $100 \mathrm{~km}$ of the coast, and c) not within ecologically protected areas were identified from digital elevation maps. In 2006, robotic stations were installed on two mountains close to the coast [5], and in 2007 another station was installed at a higher site further inland.
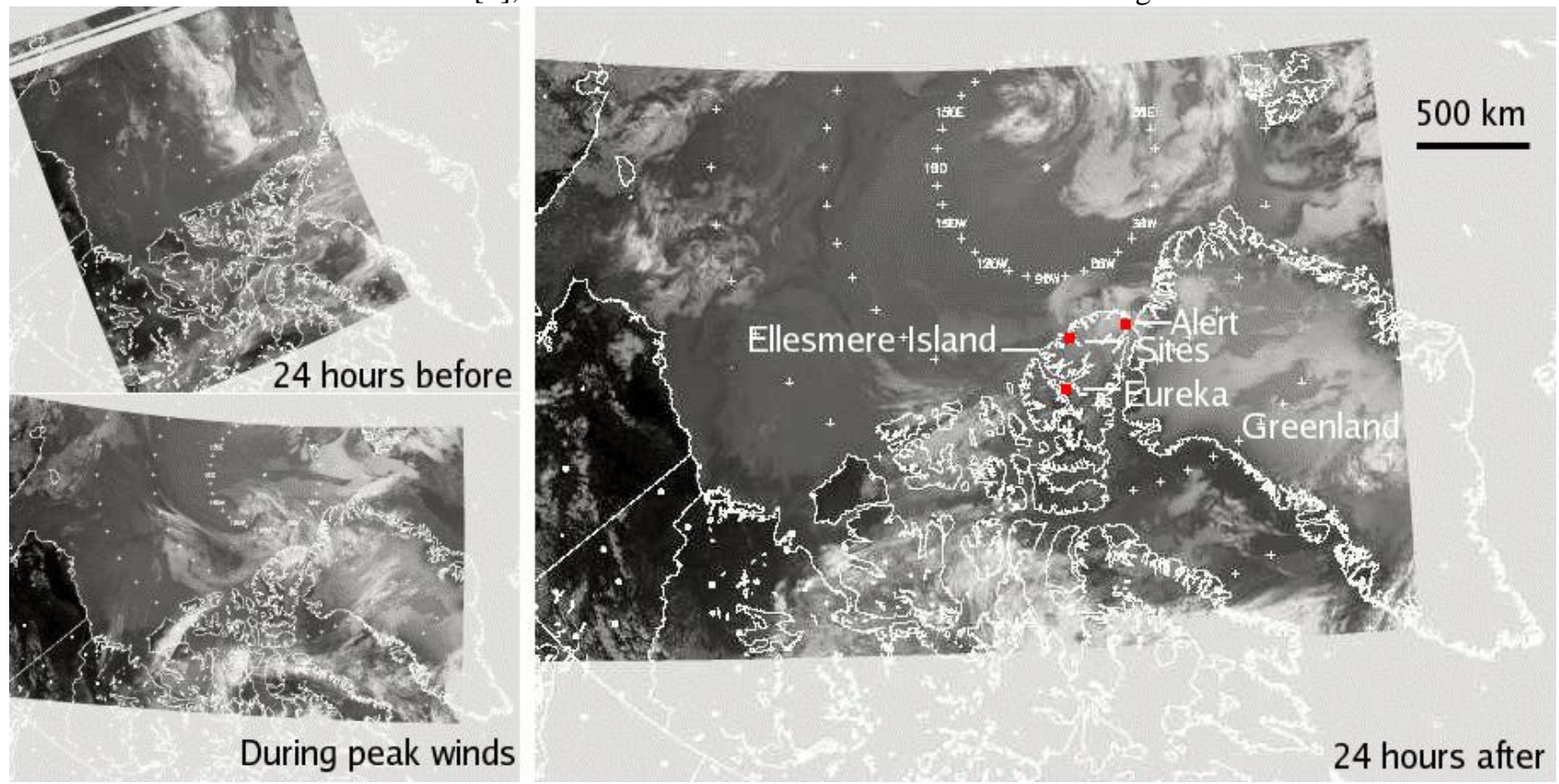

Figure 1 - NOAA polar-orbiting satellite images at 11 microns of the Arctic Ocean, northern Canada, and Greenland. Typical weather for northwestern Ellesmere Island follows a pattern of calm broken once per week or so by one to two days of westerly winds over the polar ice pack. This image sequence illustrates a "storm" on 29 August 2007, which at its peak brought sustained winds of $27 \mathrm{~km} / \mathrm{h}$ at our sites. Clear, calm conditions preceded this event, and resumed within 24 hours. 
One site is at $1098 \mathrm{~m}$ near what we label peak 11 (designated site 11A), another at $777 \mathrm{~m}$ (12A): both are on the leading edge of long rocky ridges running down to the coast. That they are rocky and relatively snow-free in summer made helicopter access easier and the solid footing of the stations more assured. These stations comprise a weather monitor, horizon-viewing camera, satellite modem, batteries, and wind-turbine power generator. A third station was installed at $1639 \mathrm{~m}(14 \mathrm{~A})$ on a broad snow-covered saddle below the 1868-m summit of peak 14. At 14A we installed a "standardized" all-sky monitoring camera (which will be discussed in more detail in a later paper) that is essentially identical to that deployed in the Thirty Meter Telescope (TMT) site testing [6]. A second modem, support computer, and additional batteries were also added to this station.

\section{AUTONOUMOUS STATIONS DEPLOYABLE BY HELICOPTER}

The selected mountain sites are only accessible by helicopter, placing constraints upon the size and mass of the site testing equipment. Using the Arctic workhorse Bell 206L LongRanger helicopter as a baseline the following constraints were derived:

- Mass limit of $200 \mathrm{~kg}$, with larger masses requiring extra trips and thereby increasing logistics costs;

- To fly safely at up to $2000 \mathrm{~m}$, this load should be internal, and because visits to the sites depend strongly on the weather it must be possible to move it quickly;

- $\quad$ Since the crew at the site might only be two, it must be of a size that can both fit in the machine and be handled by two people.

These constraints led to the development of a compact station running on batteries.

We designed and built stations that could be set up just a few hours apiece, during short windows of good flying weather in summer, and then left completely unattended over winter. Figure 2 shown images of two stations. Each comprises a:

- $\quad$ standard meteorological instrument suite for weather monitoring,

- $\quad$ wide-angle optical/near-infrared camera to image both the sky and ground conditions,

- "hardened" computer for system control,

- $\quad$ flash-based data drive,

- $\quad$ satellite modem with antenna for communications, and

- $\quad$ wind-turbine recharged central battery pack for power.

Solar panels are of no use at these latitudes in winter, and an unreasonable number of helicopter trips would be needed to carry up enough batteries to run a station through winter. All electronics are packed together with the batteries to help keep these warm, which prolongs their life. Note that an inherent disadvantage of a wind-powered approach is that it can introduce a bias: the camera is more likely to be up when it is stormy and windy. Weather data, however, are taken at all times, so this bias can be characterized. Our philosophy for the design was to make the stations small, simple and identical. In that way, each component is field swappable with another station. Since the stations are compact, they could be moved to different sites as needed, or amalgamated to one site, once selected for further study. Desirably, these basic stations can support extra instruments (possibly different for each), in addition to their standard suite. 

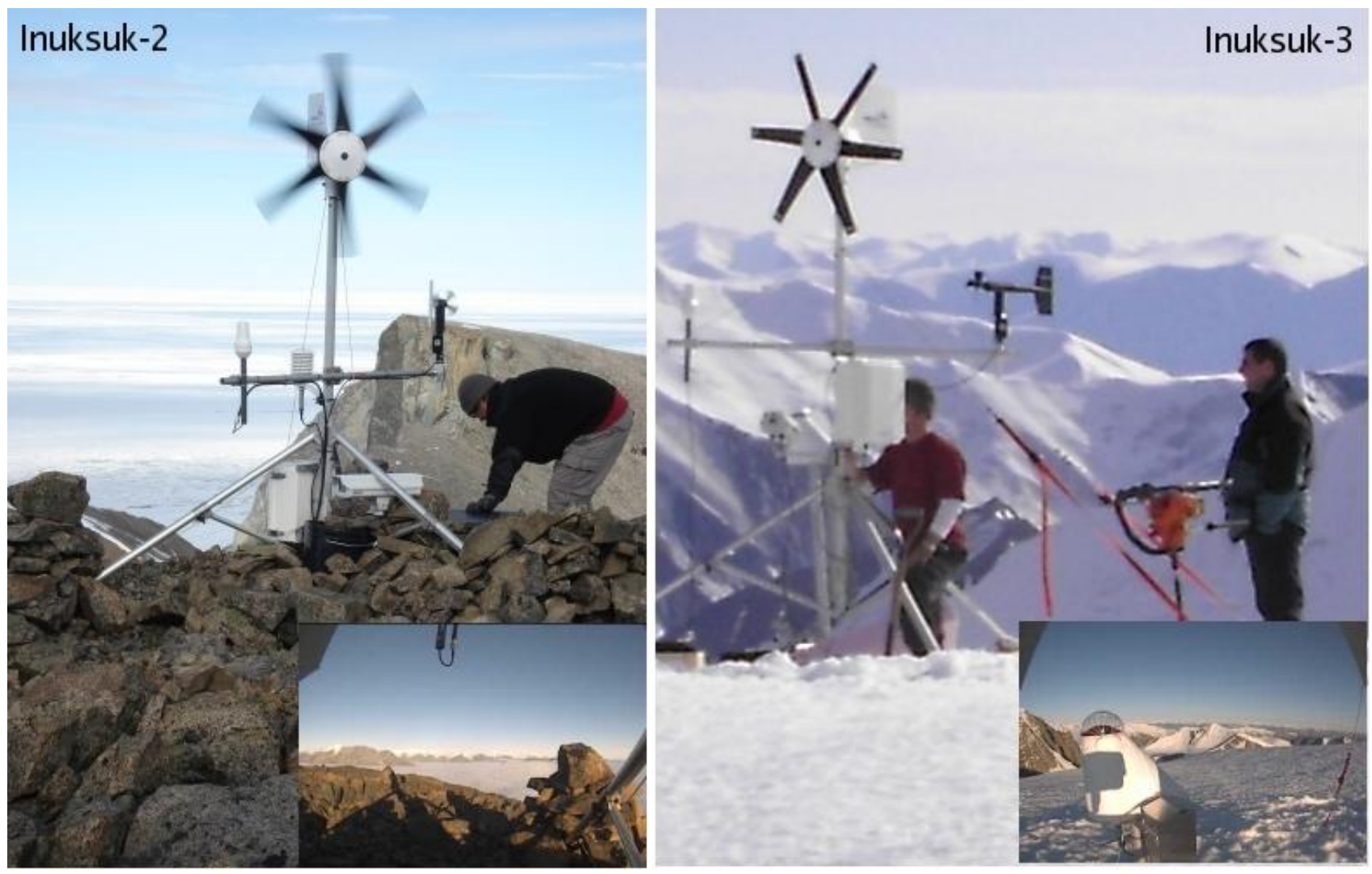

Figure 2 - Installation of a station on rock (left) and on snow (right). The piles of rock, and the general shape of the station led to the nickname "inuksuk" (pleural "inuksuit" in the local Inuktitut dialect) like the stone way-markers common in Canada's high Arctic. Inset are images taken by each station's wide-angle "horizon camera." The instrument visible in the centre of the Inuksuk-3 field of view is an all-sky camera.

\subsection{Central Tripod and Anchoring Mechanics}

The skeleton of the Inuksuit stations, to which weather instrumentation and horizon-viewing camera are attached and on top of which the wind turbine can freely rotate, is an aluminum tripod that dismantles to fit in the passenger compartment of the helicopter. Inuksuk-1 and -2 are anchored with piles of boulders, which are plentiful at sites $11 \mathrm{~A}$ and 12A. On hard snow the common approach in the Arctic is to use a powered ice-auger and a 6" $(15 \mathrm{~cm})$ flite to bore a hole in the snow. A 1-m-long wooden 4-by-4 is then inserted and snow tamped down around it. As this freezes, the post is made secure. This is the approach we used for Inuksuk-3 at site 14A. The feet of the towers were leveled and screwed down to the top of three posts. For additional support in windy conditions the tower was tied down with three guy-wires, using nylon tie-downs with ratchets at the ends to take up slack. For anchors we used snow pickets, which are aluminum " $\mathrm{T}$ " section that are set in a trench at right angles for the tower guy wire. This is capable of holding over $2.7 \mathrm{kNm}$ of force, depending on snow conditions and placement.

A future instrument for Inuksuk-3 could involve a small telescope, which will require a more solid footing than on snow alone. Measurements of depth down to ice at site 14A were made using an avalanche probe. Bore holes were also dug using the power auger. These suggest the snow is between 1 to $2 \mathrm{~m}$ deep. The ice below is hard, but can be bored with an ice auger. This would be sufficient for the solid footing of a small telescope, or seeing monitor, on a pier isolated 
from the wind-turbine tower. Further tests are to be pursued by digging deeper bore holes with a longer ice auger. Based on the surrounding terrain, rock is likely to be just a few metres below the ice, depending on the location.

\subsection{Weather Monitor}

The weather monitor consists of a Campbell Scientific CR10X measurement and data-storage module, which includes probes for temperature, relative humidity, barometric pressure, and wind. This is a standard autonomous weather monitor used in Arctic field research, has been proven dependable below $-40{ }^{\circ} \mathrm{C}$. An RS-232 interface is used to connect the weather monitor to a USB-serial port on the system controller (discussed later). The weather monitor is programmed to take measurements of battery voltage, internal control module temperature, wind speed, wind direction, outside temperature and relative humidity every $5 \mathrm{~s}$. Once per hour, the barometric pressure is measured and then the date and time, the averages of the 5-s interval measurements and the barometric pressure measurement are stored in the internal flash memory. In addition, this data is sent out on the serial port and recorded by the system controller in flash memory. The weather monitor consumes a negligible $46 \mathrm{~mA}$ and operates with a battery voltage as low as $9.6 \mathrm{~V}$. At this level it can function for one or two months without battery charging.

\subsection{Horizon Camera}

The horizon camera is an Axis 221 network camera installed in a Pelco enclosure with window defroster. The minimum rated operating temperature is $+5{ }^{\circ} \mathrm{C}$, however, the camera has been shown to operate at temperatures down to $-40{ }^{\circ} \mathrm{C}$. The camera uses a Pentax f1.0 varifocal $(3.0-8.0 \mathrm{~mm})$ lens and has an automatic iris. Focus and zoom are manually adjusted, and stable. The detector has $640 \times 480$ pixels, automatically adjusting exposure time up to $2 \mathrm{~s}$, which is sufficient for night-time imaging of bright stars. At very low light levels, the daylight infrared-blocking filter is automatically retracted.

Power is applied to the window heater a few minutes (nominally 5 minutes) before applying power to the camera in order to clear away any dew or frost. The camera automatically takes one high resolution $(640 \times 480)$ uncompressed image and one low resolution ( $320 \times 240$ ) compressed image when powered up and sends them to control computer for storage on flash memory.

\subsection{Power Supply, System Controller, and Satellite Modem}

Power is supplied by an Ampair 100 wind turbine, a robust unit modified for the Arctic by installing cold-rated bearings and grease. Significant power generation requires sustained winds exceeding $13 \mathrm{~km} / \mathrm{h}$. Output is regulated by a Xantrex C40 charge controller, storing energy in a bank of absorption glass mat batteries. Inuksuk-1 and -2 use four batteries, Inuksuk-3 has ten. Each battery can take a full charge of $33 \mathrm{Ahr}$ at room temperature, although performance degrades with cold in a predictable way. Each station's batteries are packaged together in an insulated Pelican case, which is then buried in snow for further thermal protection. All station electronics, with the exception of the weather monitor and the horizon camera, are housed within the battery box.

The weather monitor operates as an automatic power relay to the system controller (built by CamCentral Systems). Under normal conditions, this powers a BND Communications SRMS (Super Remote Monitoring System) Linux-based single-board computer, a Linksys network switch, and the DC-DC converter that provides power to the satellite modem. The weather monitor will disconnect these loads if the battery voltage drops below $11.9 \mathrm{~V}$. Power is restored when the batteries have been charged to at least $12.3 \mathrm{~V}$, which corresponds to roughly $50 \%$ full battery charge. 
A wiring flaw in Inuksuk-1 and -2 as originally deployed in 2006 led to a failure in shutting down when voltage dropped below $11.9 \mathrm{~V}$. This resulted in multiple full discharges of the batteries, causing them to fail in early October (the beginning of nautical twilight) drastically reducing the available data for that winter. This problem was fixed in 2007, and the batteries were replaced in both stations.

Figure 3 illustrates how the system controller distributes power to the horizon camera, a satellite modem, and any external instrumentation, such as the all-sky camera for Inuksuk-3. The current drawn by each of the components is listed in Table 1. The quiescent modem current $(0.1 \mathrm{~A})$ is included in the computer currents, along with the supply current of any other peripherals that are powered up along with the computers. On-times are per event; once per hour for the cameras and once per day for the modems. The Santa Barbara Instruments Group (SBIG) all-sky camera and Stealth computer (Inuksuk-3 only) are on for 5 minutes to take an image set and 7 minutes to transmit an image to the server.

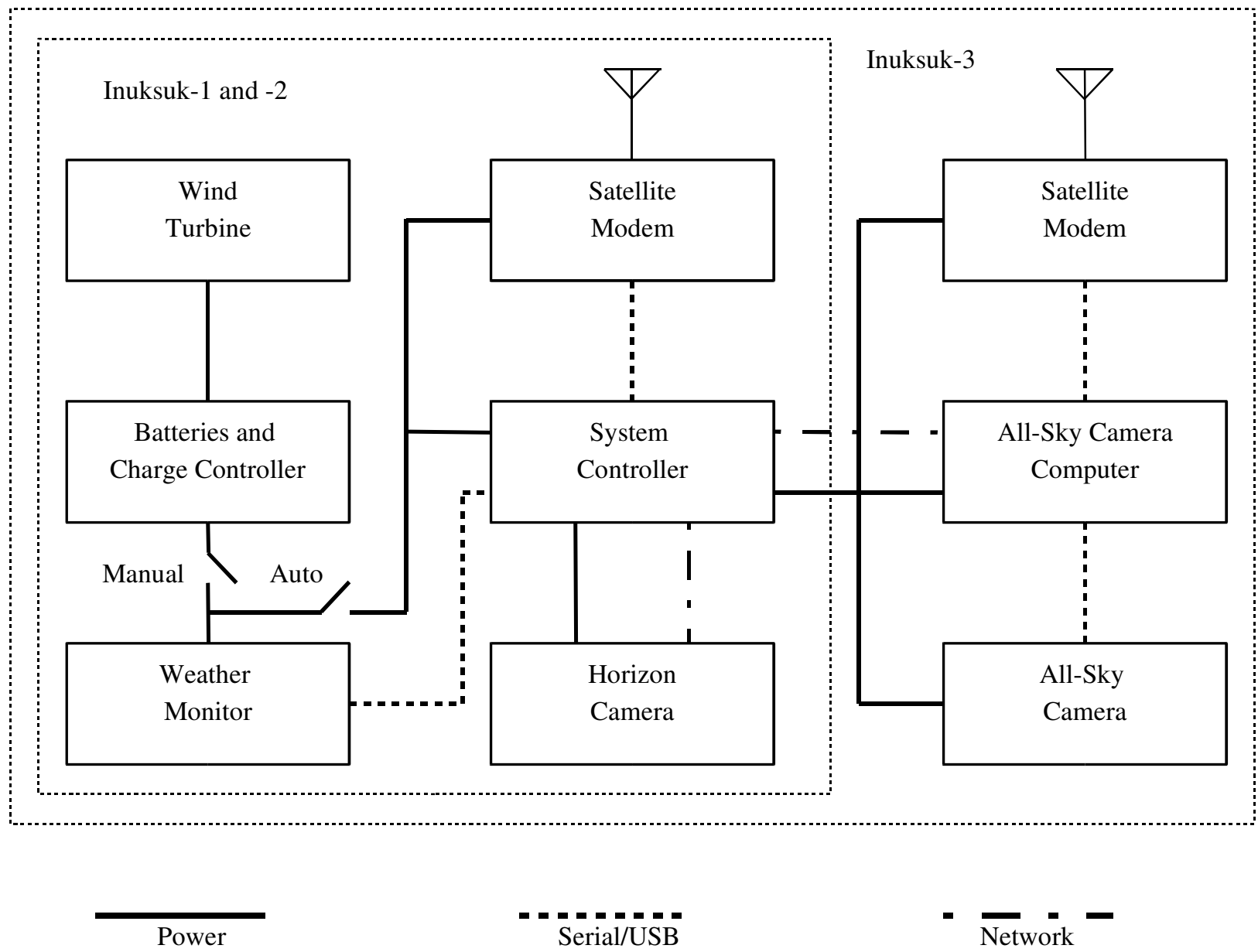

Figure 3 - Inuksuk block diagram. The basic station consists of a wind turbine power supply, batteries, a charge controller, a weather monitor, a system controller, a horizon-viewing camera, and a satellite modem. This basic station can support other instruments, for example an all-sky camera, such as that operated by Inuksuk-3. 
Table 1 Supply Currents

\begin{tabular}{|l|c|c|}
\hline Component & Current (Amps) & On-time (minutes) \\
\hline \hline System controller & 0.5 & Full time \\
\hline Horizon camera window heater & 0.2 & 7 \\
\hline Horizon camera & 0.4 & 2 \\
\hline All-sky camera window heater (Inuksuk-3 only) & 1.8 & 10 \\
\hline All-sky camera and computer (Inuksuk-3 only) & 2.8 & 5 to 7 \\
\hline Satellite modem & 1.0 & 3 \\
\hline
\end{tabular}

Satellite communications are via Iridium using a Motorola 9522A modem and antenna. This transceiver is a 2400 baud, AT-command set, radio modem with an RS-232 interface. It is rated to $-20^{\circ} \mathrm{C}$ but has been shown to operate down to $-30{ }^{\circ} \mathrm{C}$. The on-time for the modem in transmit mode is roughly $50 \%$ of the call-out time. For the modem to be idle, and remotely accessible for two-way communications whenever the Inuksuk happens to be powered up (rather than only at scheduled times), the system controller is always turned on. A benefit of this is that waste heat from the continuously operating computer (6 Watts) helps keep the batteries warm, increasing their capacity and prolonging operational life.

A disadvantage of the system controller continuously drawing power is that it reduces operational time during calm weather, when the turbine is still. Increasing the number of turbines could help counteract this, if battery storage is suitably increased. An alternative is to augment wind power, and we are investigating a small commercial fuel-cell unit which would provide a low, but continuous supply of power. It catalyzes pure methanol, producing carbon dioxide, water vapour, and heat as byproducts. Tests show that 601 of fuel, stored within the same insulated box as the fuel cell, are sufficient to operate Inuksuk-3 until at least mid-winter. The total weight is under $100 \mathrm{~kg}$, including fuel, for the trial unit we plan to deploy in 2008. It could continue to provide power even if the wind turbine were to fail. One mechanism by which turbine performance could be significantly degraded, or in extreme cases stopped altogether, is rime icing. This is a condition where super-cooled water vapour freezes onto windward surfaces, which does occur at our sites, especially in late fall to early winter.

\subsection{Onboard Data Storage}

The system controller uses an external $8 \mathrm{~GB}$ compact flash card to store images and to log weather and battery data. Each full resolution horizon camera image is about $100 \mathrm{kB}$ in size. Each low resolution image is about $10 \mathrm{kB}$ is size. Weather and battery logs are on the order of $2 \mathrm{kB}$ each. For an image and log file data set taken every hour, approximately 2800 days of storage is available. The all-sky camera computer has an internal 8 GB flash memory and two external 80 GB USB hard drives. The flash memory is used to store the JPEG images created for uploading to the home server at HIA. The hard drives are used to store the raw FITS-format images taken by the all-sky camera, for physical retrieval from the field.

\subsection{Status Reports}

When powered up, the station calls out via Iridium once per day to report the previous day's battery status and weather data. The latest low resolution horizon camera images are also sent at the same time. Data are transferred from the commercial Iridium gateway to the home server at HIA using the Internet. 


\subsection{Computer Simulation of Inuksuk Operation}

When it is windy at the sites we are able to call into the Inuksuit via Iridium and check on their status. For calm periods, when they may be shut down due to low power, we have developed a computer model in order to have a clearer picture of their status, and to estimate when they should call again. This is possible because of the remarkably regular pattern of calm weather punctuated by one to two days of strong winds at the sites, consistent with records at Eureka and Alert, as well as from the closest weather stations to ours, Ward Hunt Island, along the coast to the northeast.

The simulation prompts the user for the Inuksuk number (1,2, or 3), the number of turbines and batteries, and the year of operation. There are differences in the operational schedules between different years that the code takes into account. It then takes in the real data collected at that site and a proxy dataset, one of three full year-long datasets from Ward Hunt Island. The model interpolates between real records and extrapolates based on the proxy dataset. When no data are available, the model assumes that air temperature decreases by $1{ }^{\circ} \mathrm{C}$ per day to a minimum temperature of $-50{ }^{\circ} \mathrm{C}$ (the coldest historical record at Alert) and that winds are calm.

The power production of the wind turbine is calculated from the wind model. Subtracted from this are all the power draws from each of the systems - at the appropriate times each day. The battery charge dependence on temperature is incorporated, as is a simple model of the battery box thermal properties, and so the battery charge status follows. The system is only active when the battery charge status is above 50\% charge, and individual components only when their lower operating range is not exceeded by the battery box temperature (ambient for the weather monitor and the cameras).

The results since summer 2007 are shown for Inuksuk-1 in Figure 4. One can see that there is good agreement with the reported system voltage and battery temperature through to spring of 2008 (when those records are available). Since Iridium is not completely reliable, and calls are often dropped, the model estimates the probability of a daily call-out by multiplying the successful fraction of calls (measured prior to deployment) by the time that the Inuksuk is able to call out (voltage above $12.3 \mathrm{~V}$ ). The model suggests 48 health-status calls were expected by 1 May 2008, and 49 were actually received; roughly one per week. By using the proxy datasets and Monte Carlo methods, the simulation then estimates when another call is expected. Although this is not the same as a prediction of when the Inuksuk will next call, it is helpful in indicating if a station is long overdue in calling.

An extrapolation of data collection over the remainder of the year is made by many realizations of randomly shifting the proxy datasets by up to a week. For example, based on the model, Inuksuk-1 will take the equivalent of 78 days of hourly images ( 1900 horizon-camera images) during civil twilight and darker conditions. This is $45 \%$ of the available night-time period of 174 days. This fraction is in agreement with the true number of images that are known to have been collected on the Inuksuk-1 drive by 1 May 2008 (2838 full-resolution images to be retrieved during the 2008 field season). This is a sufficient fraction of the time to give confidence that typical conditions during Arctic night were sampled. 

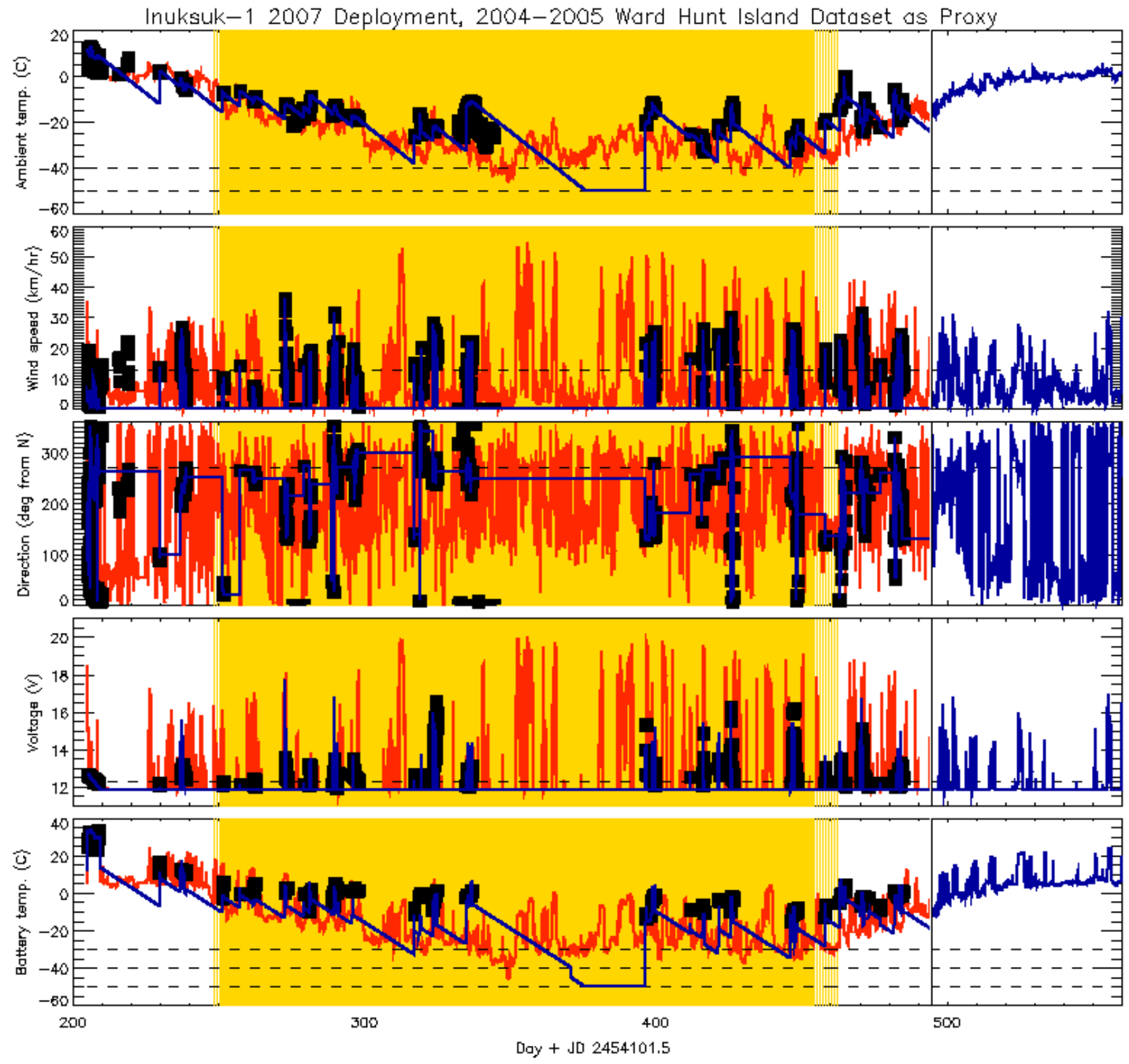

Figure 4 - Weather and health-status data reported for Inuksuk-1 since 24 July 2007 (latest maintenance visit) in Julian days. Not shown are barometric pressure, relative humidity, system current, and battery charge. Dark lines (blue in the online color version of this plot) indicate the model. Lightly shaded lines (red) are of a comparison dataset from nearby Ward Hunt Island, which is run through the same simulator. Background shading (yellow) indicates night; the vertical line 1 May 2008. Note that records are those received from autonomous calls initiated by Inuksuk-1, which are subject to availability of power and successful transfer through the Iridium network. The model knows, for example, that the modem will not operate when the battery box temperature falls below $-30 \mathrm{C}$, which may explain a lack of calls occurring in mid-winter. 


\section{PRELIMINARY DATA}

Even without the full winter dataset, it is evident that the pattern of calm winds interrupted by one-to-two days of high winds every week or so is confirmed, and that the prevailing wind direction is from the west. The current health status of the Inuksuit indicates that we will have sufficient weather data for a useful comparison of sites by summer 2008. An initial analysis of the 2006 horizon-cam data gives an idea of what will be possible when that first full year-long record becomes available in 2008 as well. The record for 2006 is - as mentioned previously - incomplete, running at site 12A only until 4 October 2006.

The horizon-camera images were viewed frame-by-frame by eye. These are easily put in bins of "completely cloudy", "mostly cloudy", "mostly clear", and "completely clear". Some small fraction of the frames were unclassified because either the frame was corrupted or the lens was covered in snow. Foggy conditions were classified as completely cloudy. A mostly cloudy frame has some patch of clear sky visible, with more than $50 \%$ of the field of view covered. A mostly clear frame has some obvious cloud, with more than $50 \%$ of the field clear. Those on the borderline were classified as mostly cloudy. A completely clear frame is just that, with possibly some faint cirrus visible. Sample images representing the four cloudiness bins are shown in Figure 5.

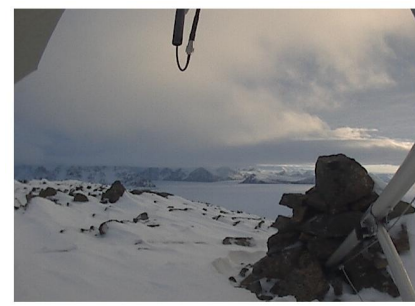

Completely cloudy

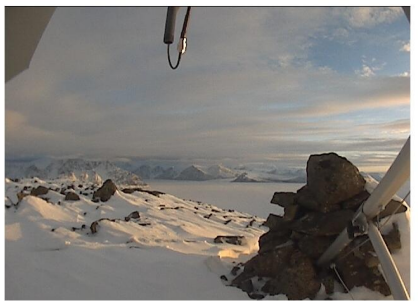

Mostly cloudy

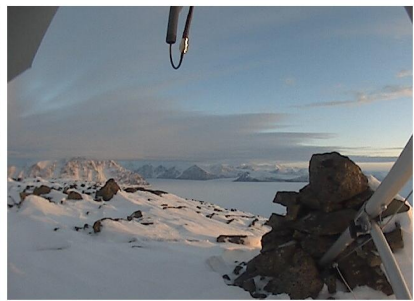

Mostly clear

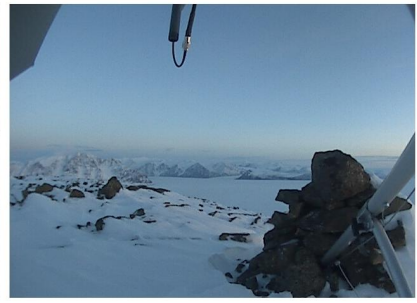

Completely clear

Figure 5 - Four consecutive hourly images taken with the Inuksuk-2 horizon camera representing completely cloudy, mostly cloudy, mostly clear, and completely clear conditions. The camera faces south; west is to the right. This sequence brackets sunset on 19 September 2006, the last image records the onset of civil twilight.

The clear-sky statistics for are plotted in Figure 6 versus wind speed, for Inuksuk-2 in 2006. It is readily apparent that there is a correlation between low ground wind speed and clear skies. Essentially, skies clear when winds drop below the median wind speed of $5.4 \mathrm{~km} / \mathrm{h}(1.5 \mathrm{~m} / \mathrm{s})$. This confirms the expectations from the satellite images that show that clear skies quickly follow the passing of storms. Note that this result accounts for the bias of taking images preferentially when winds are high. The Inuksuk takes weather data at all times, so we know what fraction of the time winds are less than $1.5 \mathrm{~m} / \mathrm{s}$, although the camera is less likely to be powered up at those times to record the sky conditions. 


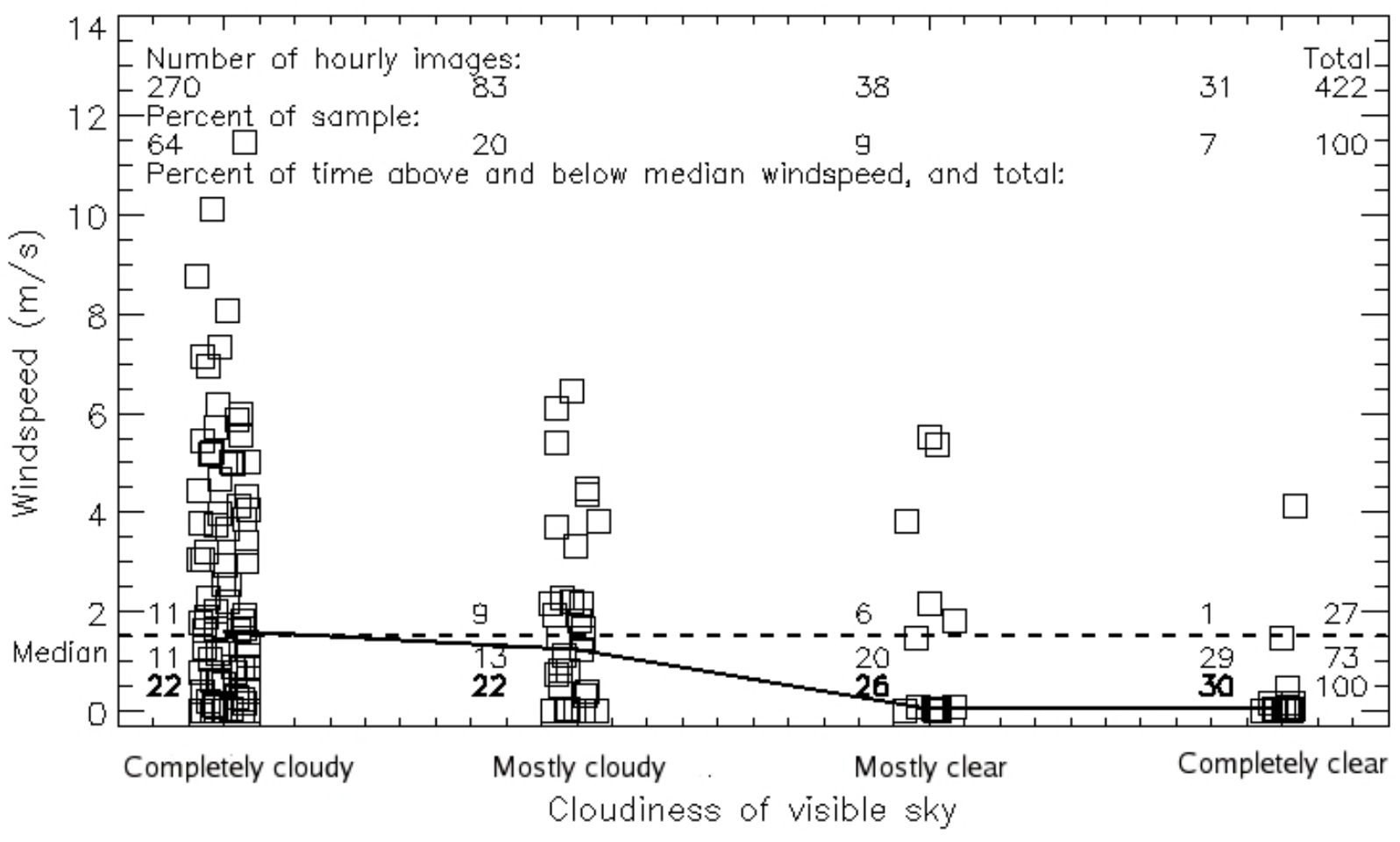

Figure 6 - A plot of observed ground wind speed as a function of cloudiness of visible sky in horizon-camera images for Inuksuk-2 in 2006. This record is only of mid-summer through to the onset of nautical twilight, ending on 4 October 2006. A strong bias towards collection of sky data (but not weather information) during windy periods is evident. Small random offsets have been applied in each cloudiness bin to help show the change in these distributions with mean wind speed (solid line) against the global median (dashed line). The wind-induced bias is greatly reduced for data collected since summer 2007 due to correction of a wiring flaw in the original deployment. Even so, already the first data give a strong indication of clear skies associated with calm winds, as expected from satellite images.

\section{SUMMARY AND FUTURE PLANS}

We have discussed the deployment of autonomous site-testing stations that record winter weather and sky conditions on three Arctic mountain sites. By the 2008 field season we will have a full year's data from the high site (14A) and somewhat more from the two lower sites (11A and 12A). A preliminary estimate of cloudiness in summer/fall has already been made based on the initial horizon-camera images from 2006. Subsequent datasets are to be pinned to one site employing a standardized all-sky monitor. Comparison to satellite measurements is also possible.

In 2008 we plan to deploy a simple seeing monitor at one site. This device, which takes a series of short exposures of Polaris and measures the tip-tilt component of seeing is intended for Inuksuk-3. A more sophisticated turbulence profiler, employing lunar scintillometry, is being developed for deployment in 2009. These instruments will be discussed in later papers. If atmospheric conditions are as good as expected, installation of a small, scientifically productive telescope could occur as early as 2009. An ultimate long-term goal is a large telescope specialized in the thermal infrared. 
Acknowledgements

Many individuals are to be thanked for their help with this work: Liviu Ivanescu for his satellite analysis; Derek Mueller for providing the Ward Hunt Island weather data; Michael Ashley, Zoran Ninkov, and Ron Verral for helpful discussions; Mubdi Rahman and Johnathan Klein for assistance with mapping and field work; Ron McOuat, Peter Turner, and Dennis Milligan for initial system controller integration, David Loop, Darren Erickson, and Karen Inootik for their advice, Ajaz Mirza for wiring and cabling assistance; Bob Wooff for assistance in assembling and wiring the battery packs; Will Kastelic for network support and debugging; Kris Caputa for Linux support; Murry Fletcher for guidance on optics; Jim Jennings, Gordon Hnylycia and Colin Ganton for mechanical fabrication and support; and Mike Hare and Ian McCrea for purchasing and shipping expertise. This research was supported by funds from the Natural Sciences and Engineering Research Council of Canada, the National Research Council of Canada, Defence Research and Development Canada, and Environment Canada. Support from the Polar Continental Shelf Project is through Natural Resources Canada, and we particularly thank their staff and pilots.

\section{REFERENCES}

[1] www.eso.org/ livanesc/poles/np/ Canadian High Arctic, 130

[6] Walker, D.E., Schwarz, H.E., \& Bustos, E., 2006, Monitoring the night sky with the Cerro Tololo All-Sky camera for the TMT and LSST projects, Proc. SPIE, Vol. 6267, 62672O-1 